\title{
INTERRELATIONS OF MAGNESIUM, POTASSIUM, PHOSPHORUS, AND CREATINE IN SKELETAL MUSCLE OF MAN ${ }^{1}$
}

\author{
By DAVID BALDWIN,22 PETER K. ROBINSON,3 KENNETH L. ZIERLER, AND \\ JOSEPH L. LILIENTHAL, JR. \\ (From the Departments of Medicine and of Environmental Medicine, The Johns Hopkins \\ University and Hospital, Baltimore, Md.)
}

(Submitted for publication May 28, 1952; accepted July 16, 1952)

In latter years the growth of methods has led to a detailed understanding of the concentration and distribution patterns of electrolytes and water in the extracellular liquids. More recently attention has been directed toward the intracellular phase. The greater bulk of observations has been concerned with the most abundant intracellular cation, potassium. Much less is known about magnesium, second only to potassium with respect to concentrations within cells.

There are many indications of the intimate role which magnesium plays in modulating neural excitability and muscular contraction (1-7); in catalysing several enzymic processes concerned with the transfer, storage and utilization of energy (8-14) ; and, perhaps, in the adjustment of overall bodily economy reflected in temperature regulation and hibernation $(15,16)$. Yet little is known of the patterns of its ebb and flow into and out of cells, or, indeed, of the concentrations obtaining within cells during most diseased states. This study was begun in order to discover what changes, if any, occurred in the magnesium content of skeletal muscle during certain clinical states marked by disturbances of electrolyte metabolism and accompanied occasionally by asthenia.

For purposes of reference, concentrations of magnesium and of potassium in muscle were measured at the same time. It soon became apparent that even in the most diverse states of disease, as well as in health, an extraordinarily fixed relationship obtained in muscle between concentra-

\footnotetext{
1 Aided by a contract between the Office of Naval Research, Department of the Navy, and The Johns Hopkins University (NR 113-241).

2 Postdoctorate Fellow of the National Institute of Arthritis and Metabolic Diseases, U. S. Public Health Service. Present address: The Presbyterian Hospital, Chicago, Illinois.

${ }^{8}$ Fellow in Neurological Medicine, supported by the Nuffield Trust. Present address: The National Hospital, Queen Square, London W. C. 1, England.
}

tions of magnesium and of potassium: the two major cations had entered or left the muscle cell in such amounts as to maintain a constant relation one to the other. This observation suggested further analysis of the relation held by these cations, potassium and magnesium, to representative intracellular anions. Phosphorus and creatine were selected for study because of their abundance, their relation to each other as creatine phosphate and to potassium in phosphorylating reactions (17-19), and because of observations which have suggested that potassium and phosphorus cross cell barriers in a relatively fixed proportion (20-22).

\section{MATERIAL AND METHODS}

All samples of muscle for analysis were obtained by biopsy. The normal series was secured from 15 patients undergoing surgical procedures under general anesthesia for conditions not associated with clinical or chemical evidence of disturbed electrolyte metabolism. The remaining 15 samples were obtained by surgical excision under local procaine anesthesia of overlying tissues; no anesthetic solution was introduced below the overlying muscle sheath. Five such samples were taken from muscles which had undergone extensive atrophy. Another five samples were excised from the gastrocnemii of patients who, because of a variety of diseases, had developed hypokalemia. The final five samples of muscle came from patients who had developed hyperkalemia in association with severe renal failure owing to several causes. Because the underlying disease process was complex in each instance, the patients were divided arbitrarily into these two groups on the basis of a predominant pattern. For example, patients L. W. and A. M. were assigned to the hypokalemic group because the concentrations of potassium in serum were at the lower limit of the normal range.

The samples of muscle were excised, quickly blotted to remove superficial blood, and trimmed of any obvious tendinous or fascial shreds. A representative portion of each sample from the abnormal groups was separated at once and fixed for microscopic study. The muscle was then frozen rapidly by introducing it into a glass container packed in dry ice. Subsequently, the muscle was split into fragments which were weighed in the frozen 
TABLE I

Nitrogen content of muscle fat

Gm. fat per
fresh mu
4.4
9.5
10.4
14.1
20.0
35.1
74.8

$\begin{array}{cc}\begin{array}{c}\text { Gm. N per } 100 \mathrm{gm} . \\ \text { extracted fat }\end{array} & \begin{array}{c}\text { \% error in } \\ \text { total NCN }\end{array} \\ .4 & .7 \\ .5 & 2.2 \\ .5 & 2.0 \\ .5 & 2.5 \\ .3 & 2.9 \\ .6 & 8.9 \\ .5 & 15.2\end{array}$

state in a refrigerated balance. Duplicate, usually triplicate, and occasionally quadruplicate fragments, weighing between 0.5 and $1.0 \mathrm{gm}$., were homogenized in glass-distilled water by a Lucite pestle and tube modified from Potter's design (23). The basic system of analysis of the aqueous homogenates followed that previously described (24). Creatine was determined in the alkali digest as creatinine by the method of Peters (25). Fat content was estimated by extracting the aqueous homogenate with ethyl ether and weighing the dry residue. The fat was then analyzed for its nitrogen content. With only a few exceptions, chemical analyses were performed in triplicate on each homogenate made from each of three or four fragments of a single sample of muscle.

The continuing problem of selecting a base to which to refer the concentrations of intracellular constituents has been discussed before (24). Experimentally induced muscle atrophy has been studied in rabbits (26); and with atrophy, that fraction of total muscle protein provided by collagen became proportionally larger as in- trafibral protein was lost. Such a dilution of true muscle by fibrous or other non-muscular tissue in certain diseased states led to the adoption of non-collagenous nitrogen $(\mathrm{NCN})$ as a reference base in order to set one parameter in terms of an intracellular substance rather than a mixed anatomical mass of muscle cells and extra-

TABLE II

\section{Subject Siex Age Diagnosis}

\section{ATROPHY}

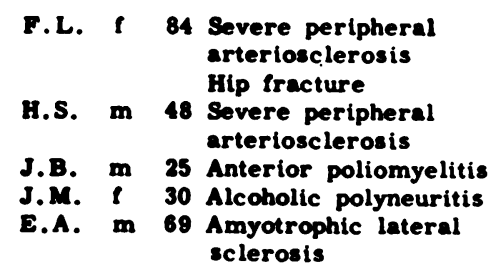

\section{HYPOKALEMIA}

L.W. I 48 Chronic pyelonephritis V.C. I 23 Ulcerative colitis

C.H. I 34 Lymphosarcomatosis (with protracted emesis)

A.M. I 63 Adenocarcinoma of esophagus with metastases to bone

M.H. I 46 Hypertensive cardiovas cular renal disease; salt losing syndrome

\section{SERUM CONCENTRATION}

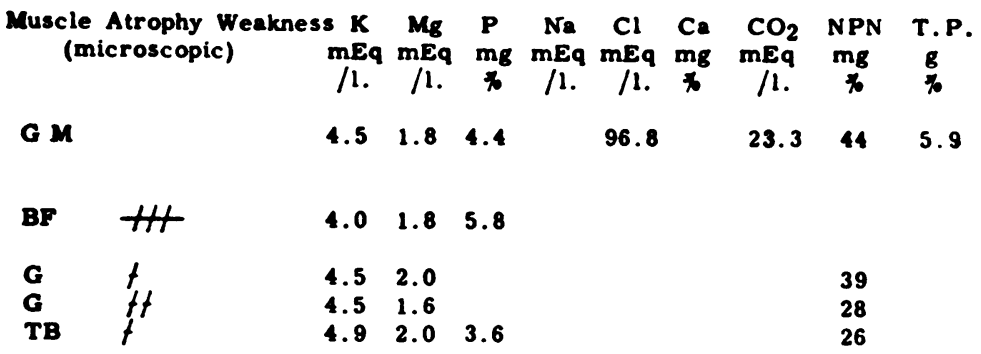

$\begin{array}{lllllllllllll}\text { G } & 0 & \text { ff } & 3.5 & 1.0 & 4.7 & 98 & 76.5 & 7.8 & 14.5 & 93 & 5.9 \\ \mathbf{G} & 0 & \text { ft } & 2.7 & 2.1 & 2.7 & 131 & 94.1 & 9.0 & 20.0 & 29 & 6.3 \\ \mathbf{G} & 0 & \text { fff } & 2.5 & 1.5 & 2.4 & 131 & 85.8 & 20.8 & 39.0 & 50 & 5.6 \\ \mathbf{G} & \text { ff } & \text { ff } & 3.7 & 1.6 & 2.8 & 138 & 104 & 17.1 & 30.0 & 40 & 7.3 \\ & & & & & & & & & & & & \\ \text { G } & 0 & \text { ff } & 4.4^{2} & 3.3 & 7.1 & 115 & 79.0 & 7.5 & 17.4 & 104 & 4.9\end{array}$

HY PERKA LEMLA

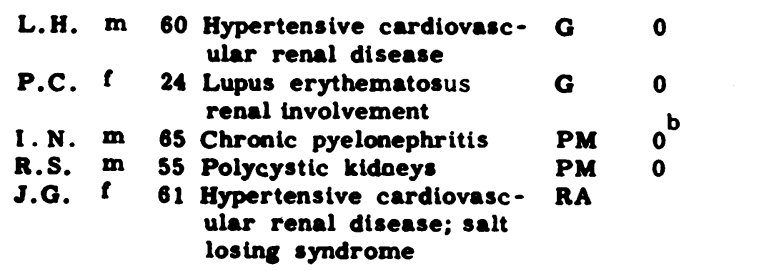

$\begin{array}{lrrrrrrrrr}0 & 6.4 & 2.5 & 5.2 & 125 & 104 & 6.2 & 21.0 & 121 & 5.9 \\ f & 7.3 & 2.3 & 4.8 & 144 & 106 & 8.5 & 20.0 & 128 & 4.8 \\ 0 & 5.2^{c} & 1.6 & 8.9 & 127 & 98 & 8.1 & 9.4 & 122 & 7.0 \\ 0 & 5.7 & 2.2 & 6.6 & 144 & 109 & 10.2 & 21.2 & 125 & 5.9 \\ f f & 6.2 & 2.5 & 3.0 & 145 & 94.38 .8 & 23.2 & 130 & 6.9\end{array}$

G - Gastrocnemius

PM - Pectoralis major

BF - Blceps femoris

TB - Triceps brachii

GM - Cluteus medius

RA - Rectus abdominis a. Potassium values in this patient had ranged from 2.5 to $3.1 \mathrm{mEq} / 1$. during the week prior to biopsy. Value obtained the day before was $3.1 \mathrm{mEq} / \mathrm{l}$.

b. Grossiy atrophic muscle mass. No microscopic evidence of atrophy in small fragment sectloned.

c. Potassium values in this patient had renged from 6.0 to $6.3 \mathrm{msq} / 1$. during the week prior to biopsy. Value obtained the day before was $6.2 \mathrm{msq} / 1$.

d. Sodium values in this pattent had ranged from 126 to $135 \mathrm{~m} 5 \mathrm{~g} / 1$. during the two weeks prior to biopsy. 
TABLE III

MUSCLE CONCENTRATION

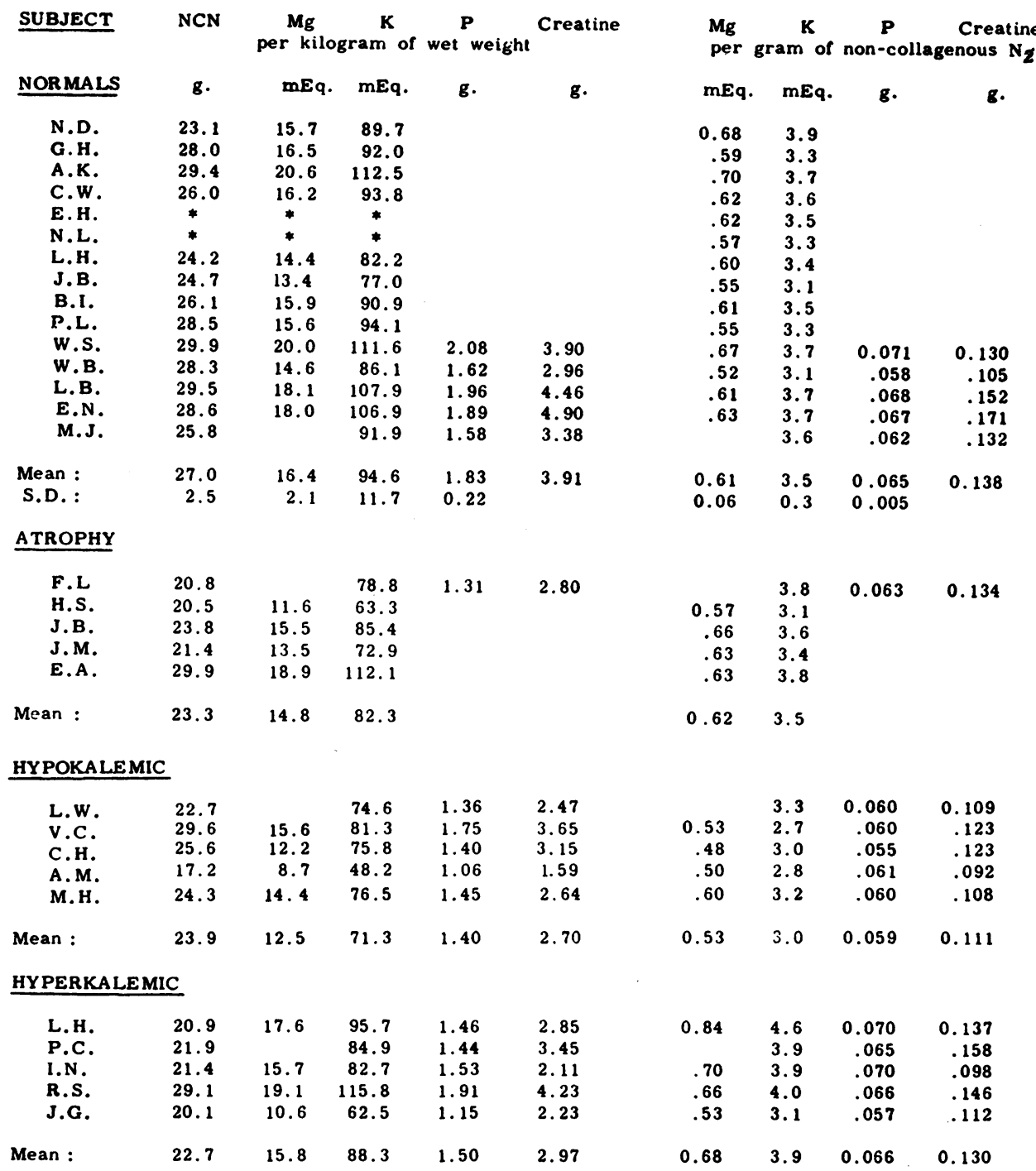

* Owing to an error in dilution, only the ratios of electrolyte to NCN were obtained.

fibral tissues. Support for the validity of this analysis appears below in the study of atrophied muscle where the apparent depletion of magnesium, potassium and phosphorus (referred to wet weight) vanished when these same elements were referred to an intracellular substance, NCN, an index of intrafibral protein (Table III).

The question of the size of the contribution to the total NCN by the nitrogen contained in fat was examined. As demonstrated in Table I, the nitrogen contributed by fat, but appearing as $\mathrm{NCN}$, becomes significant only when the fat content of the muscle sample exceeds one-fifth. The NCN values for all muscle samples of the hypokalemic and hyperkalemic series were corrected for NCN contributed by fat. In only two specimens of muscle did the fat content of the muscle exceed 20 per cent.

The values determined, which are expressed to imply that they represent intracellular concentrations, have not been corrected for the contribution of these substances from the intravascular and interstitial spaces. Because of the high concentration gradients between the intra- and extracellular phases, it may be calculated that the error introduced by failure to apply this correction does not exceed 2 per cent. 


\section{RESULTS}

The clinical material and the concentrations of the various constituents in serum on or before the day of biopsy are presented in Table II. In these laboratories the normal range for serum magnesium is 1.7 to $2.2 \mathrm{mEq} . / 1$. and for serum potassium 3.5 to $5.0 \mathrm{mEq}$. $/ 1$. The concentrations found in the samples of muscle appear in Table III. The values for normal muscles were of the same order as those calculated on a fat-free basis by Shohl from the literature (27). The ionic concentrations in atrophied muscle, when referred to $\mathrm{NCN}$, were the same as those discovered in normal muscle, an inevitable result of the proportional depletion both of ions and of contractile proteins.

When the concentrations of potassium and of magnesium were plotted as a ratio, this ratio appeared to be constant and equal for all samples studied, whether from normal subjects, atrophied muscle, or from patients with frank disturbances of electrolyte metabolism (Figure 1). In this figure each point represents the mean value of two or three fragments from one sample of muscle. The average variation from its mean within each group of fragments was less than 5 per cent. The regression curve intercepts the origin.

A similar fixity of the concentration ratios for $\mathrm{K} / \mathrm{P}$ (55.1, S.D. $= \pm 4.6$ ) and for $\mathrm{Mg} / \mathrm{P}$ (9.5, S.D. $= \pm 0.8$ ) was found (Figure 2). However, a linear extrapolation of these regression curves intercepts the abscissa at a value corresponding to approximately one-third of the content of total potassium in normal muscle (Figure 3 ).

The relations of the concentrations of potassium (and therefore of magnesium) to those of creatine

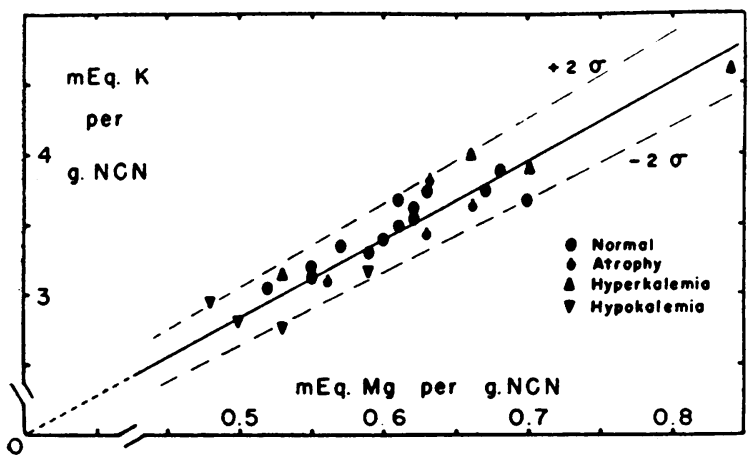

Fig. 1. Relationship Between K and Mg in 26 Muscle Biopsies

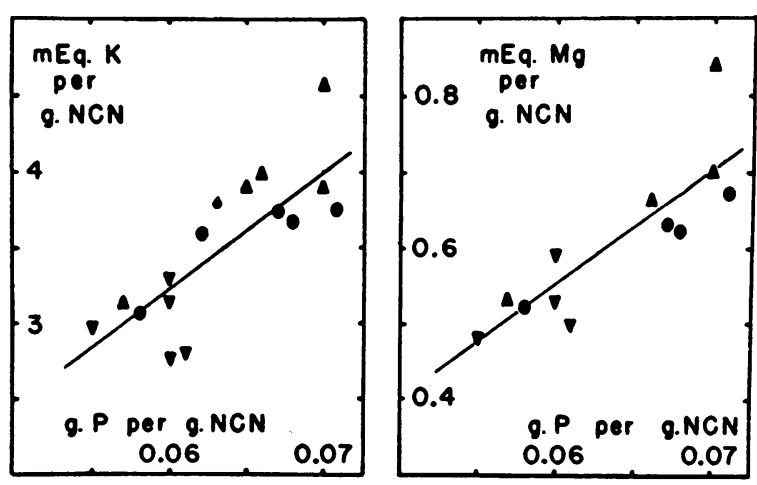

Fig. 2. Relationship Between $K$ and $P$, and Mg and $P$ IN MUSCle Bropsies

were less clear (Figure 4). Nevertheless, if the samples are divided arbitrarily into two groups on the basis of their having contained more or less than $3.5 \mathrm{mEq}$. $\mathrm{K}$ per $\mathrm{gm}$. $\mathrm{NCN}$, the mean normal concentration, then there was a statistically significant reduction in creatine content in those muscles with diminished amounts of cation.

The wide variations in the ratios of potassium to magnesium obtaining in serum, in sharp contrast to the small variation in muscle, are presented in Figure 5. A three-fold increase in the $\mathrm{K} / \mathrm{Mg}$ ratio in serum was accompanied by no significant change in the ratios of muscle. The same constancy of the $\mathrm{K} / \mathrm{P}$ and $\mathrm{Mg} / \mathrm{P}$ ratios in muscle were found despite a five-fold variation of these same

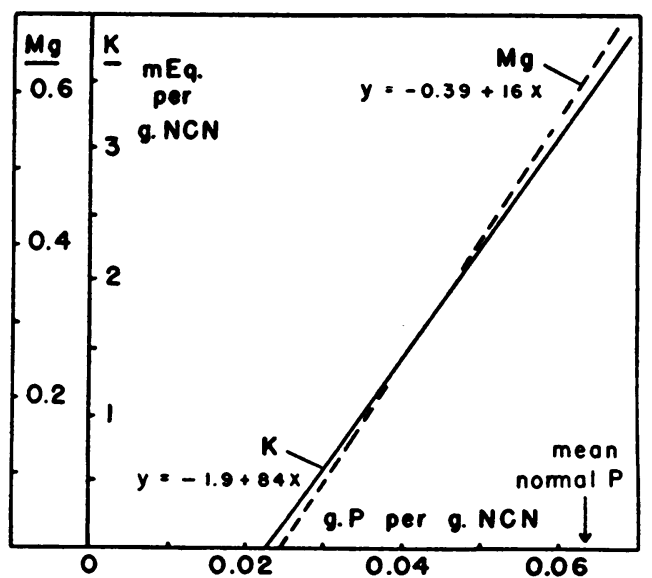

Fig. 3. Regression Curve Calculated from Data of FIG. 2

When concentration of $\mathrm{K}$ is zero, $\mathrm{P}=0.023 \mathrm{gm}$. per gm. NCN. Normal $P$ concentration $=0.063 \mathrm{gm}$. per $\mathrm{gm}$. NCN. 


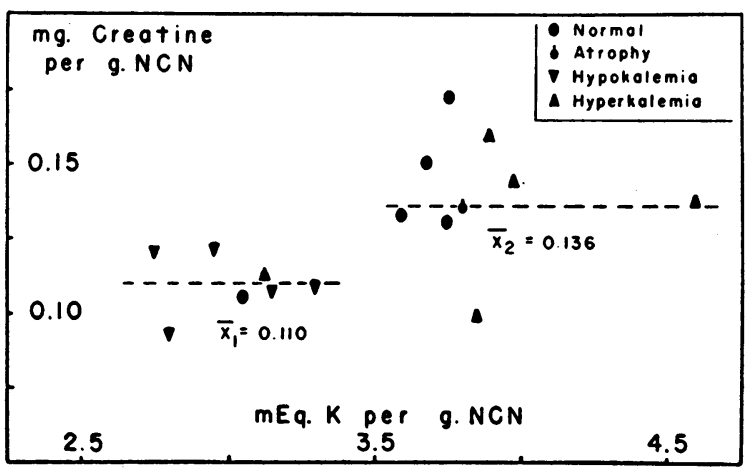

Fig. 4. Relationship of Creatine and $\mathrm{K}$ in Muscle

The mean creatine of the "low" $\mathrm{K}$ group is 0.110 , of the "high" $\mathrm{K}$ group is $0.136 \mathrm{gm}$. The probability, calculated from the " $t$ " test, that this difference occurred by chance is less than one in 50 . " $\mathrm{t} "=2.82 ; \mathrm{P}<0.02$.

ratios in serum. In this limited series, a significant depletion of muscle $\mathrm{K}$ accompanied hypokalemia in two of five instances; and at least two of the five patients with hyperkalemia were found to have appreciable intracellular accumulations of potassium. Because of the coupled relation of the major cations, the magnesium contents of muscle reflected those of muscle potassium but showed no clear relation to the concentrations of magnesium in serum.

The ratios of serum potassium (mEq./l.) to muscle potassium (mEq./gm. NCN) average about 1.3 in normal subjects. In the hypokalemic group the average ratio was $1.1(0.8-1.3)$; and in the hyperkalemic group it was $1.6(1.3-2.0)$. The small groups reported here do not lend themselves to valid analysis, but it is of some interest to note that in each group, that patient with the

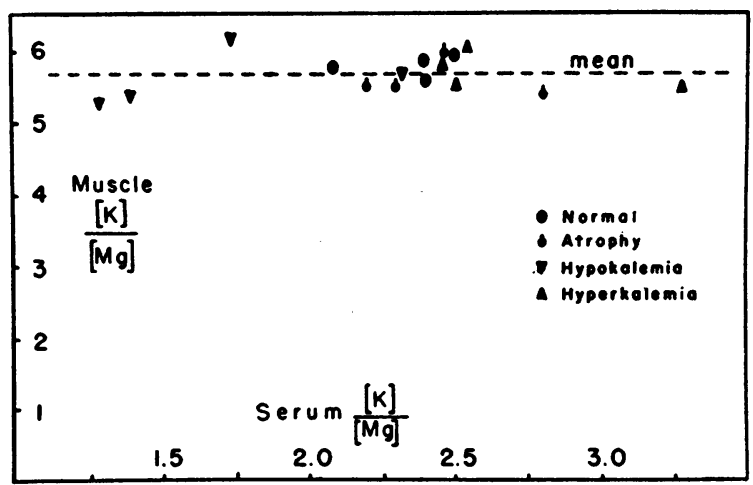

Fig. 5. Independence of Muscle Ratios and Serum Ratios of $\mathrm{K}$ to $\mathrm{MG}$ most divergent ratio also exhibited the greatest degree of muscular weakness as assessed by relatively crude clinical measurements.

The constancy in muscle of the ratios $\mathrm{K} / \mathrm{Mg}$, $\mathrm{K} / \mathrm{P}$ and $\mathrm{Mg} / \mathrm{P}$ might suggest that these relations followed necessarily the simple reduction or accumulation of muscle tissue containing a normal protoplasmic pattern, and thus no differential loss or gain of any intracellular constituents had occurred. That this is not likely to have been the case is indicated in Figure 6, where it may be seen that the relation of potassium (and, therefore, of $\mathrm{Mg}$ and $\mathrm{P}$ ) to $\mathrm{NCN}$ was random. In muscles ranging in content of $\mathrm{NCN}$ from 20 to $30 \mathrm{gm}$. per $\mathrm{kgm}$. wet weight, the potassium content was found

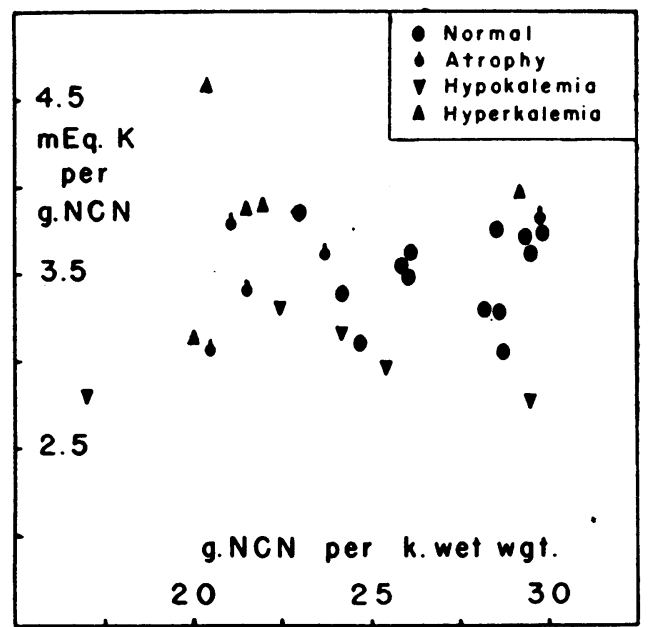

Fig. 6. Random Relation of $\mathrm{K}$ PER MgM. NCN to NCN PER KGM. OF WET Weight

to vary through a range of $1.1 \mathrm{mEq}$. per gm. $\mathrm{NCN}$, or approximately one-third of the mean total potassium content. The most striking example was seen in patient $\mathrm{L}$. $\mathrm{H}$. in whose gastrocnemius the $\mathrm{NCN}$ was reduced to $20.9 \mathrm{gm}$. per $\mathrm{kgm}$. wet weight, while $K$ had accumulated to a concentration of $4.6 \mathrm{mEq}$. per gm. NCN (Table III). This variation indicates that the changes discovered were not the result simply of dissolution or expansion of normal intracellular mass.

\section{DISCUSSION}

Direct determinations of intracellular magnesium, potassium and phosphorus in human skeletal muscle have demonstrated an extraordinarily fixed 
relationship of these substances in the face of wide distortions in the pattern of the extracellular milieu. This observation was unexpected, for there are several reports indicating that in the muscles of rat and frog, magnesium, potassium, and phosphorus may rise and fall in reciprocal or even dissociated fashion (28-31). However, other studies are consonant in whole or in part with the relation of these intracellular constituents which has been described here. For example, potassium is known to move with inorganic phosphate into the cell in conjunction with the phosphorylation of glucose $(21,32)$. A linked transfer of this same kind has been seen in the simultaneous fall in serum concentration of potassium and of inorganic phosphorus following the intravenous infusion of glucose, fructose, and epinephrine (33), and following the injection of insulin in dogs (20). In the latter case, following insulin, there was also a slight but consistent fall in serum magnesium. Recently Eliel, Hellman, Pearson, and Katz (22) have demonstrated a simultaneous loss of intracellular potassium and phosphorus from skeletal muscles of patients under treatment with adrenocorticotropic hormone or cortisone.

Evidence supporting the premise that magnesium is also closely related in the net flux of intracellular substances, has been more indirect. Fenn and Haege's study of frog muscle showed that magnesium might move in the same or opposite direction with respect to potassium, depending on the kind of external or internal stress which was applied (29). Furthermore, from balance studies during the onset and treatment of diabetic acidosis, it was estimated that several cations were wasted or saved in proportion to the fraction of intracellular base which they formed (34, 35). As a consequence Butler has emphasized the necessity for a simultaneous repair of the deficit of intracellular potassium, magnesium and phosphorus in diabetic acidosis (36). Additional support for this view is implicit in the observation that the serum concentrations of all three substances fall simultaneously following the initial therapy of diabetic acidosis with insulin and $\mathrm{NaCl}$, and the presumed transfer of intracellular constituents from the extracellular fluids into cells (37).

Mangun, Reichle and Myers reported a de- crease in potassium, phosphorus and creatine content of skeletal muscle in patients who had died in congestive heart failure (38). This deficiency they interpreted to be the net effect of a simultaneous escape of these three substances from the "cells" following the breakdown of a di-potassium salt of phosphocreatine. Such an explanation would appear to be inadequate now to explain the relation of potassium, phosphorus and creatine reported here. If the linear extrapolation of the cationphosphorus ratio in Figure 3 be valid, some 60 per cent of total phosphorus is related to cell cation. However, not more than 20 per cent of total phosphorus is known to be present in the form of phosphocreatine (39). The difference, 40 per cent of the total, then, represents the approximate amount of phosphorus related to cell cation but not associated with creatine. It is unlikely, therefore, that the association of the flux of potassium, magnesium and phosphorus described in this report is more than a partial function of phosphocreatine synthesis and hydrolysis. The observation that patients with supernormal accumulations of intracellular potassium did not develop comparably elevated creatine concentrations is additional evidence against the inference that potassium accumulates in the cells only as a result of the synthesis of phosphocreatine.

One possible interpretation of the association of an intracellular potassium deficit with a deficit of creatine is that normal synthesis of phosphocreatine requires an adequate concentration of intracellular electrolyte. Phosphocreatine synthesis in this case would be dependent on muscle electrolyte content, rather that the reverse. Such a relation is consonant with certain recent knowledge of creatine metabolism. Several investigators have described the essential role of potassium in phosphorylation of creatine in vitro (17-19). On the other hand, it is probable that supernormal accumulations of potassium are not accompanied by comparable storage of creatine because the muscle has become saturated with respect to creatine, which, as has been shown for the rat, cannot be stored in amounts greatly exceeding that which occurs normally $(40,41)$.

The justification for using serum magnesium, potassium and phosphorus concentration ratios as indices of comparable interstitial fluid ratios may be questioned on the grounds that the degree 
of binding of these substances may vary. Previous reports have indicated, however, that serum potassium exists in a state in which its distribution between serum and interstitial fluid conforms to the values predicted by the Gibbs-Donnan equilibrium $(42,43)$. Serum phosphorus has long been known to exist in a similar state, the fraction bound to serum protein being small (44). Although high proportions of bound to total magnesium in serum have been reported to occur in hyperthyroidism (45), in most other states the proportion is sufficiently stable so that it is likely that the wide range in concentration in total magnesium in sera reported here was reflected at least approximately by a similar wide range in concentration in magnesium in interstitial fluid. On the assumption, then, that concentration ratios of serum electrolyte ratios provide approximate indices of similar interstitial fluid proportions, the conclusion has been drawn that gross distortions in composition of extracellular fluid and wide variations in electrolyte concentration gradients need not be accompanied by any change in the proportionality of potassium, magnesium, and phosphorus in the cell. Attention may be drawn to the fact that by no means all examples of intracellular electrolyte distortions have been studied. The possibility remains, therefore, that the fixity of intracellular concentration ratios might fail 1) in the course of abrupt shifts of an acute nature or 2) in the face of other diseases not examined.

It would appear, nevertheless, that whatever may be the mechanism responsible for the maintenance of fixed proportions of these electrolytes in muscle, it continues to operate effectively during certain states of depletion or of accumulation, and to defend these constant relationships during extensive alterations produced in interstitial liquids by impaired function of kidney and bowel. This conclusion implies that attempts to repair intracellular deficit of potassium and phosphorus might be accompanied reasonably by simultaneous repletion of magnesium, and perhaps several other constituents of muscle cells.

With respect to possible mechanisms concerned in the guarding of concentration ratios of intracellular electrolytes there are no data reported here which resolve substantially the differences to be found in current concepts. These interpretations vary from those which imply that the reten- tion or exclusion of ions is the result wholly of active "pump"-like mechanisms to those which suggest that pure physicochemical forces such as charge, density, and spatial arrangement of the intracellular proteins and ions, are alone responsible for the gradients which occur (46). The interrelations which have been described in this report are compatible with either mechanism or, perhaps, with both.

Initially, these studies were undertaken in the hope that there might be disclosed some coordinated relation between the pattern of intracellular electrolytes and the occurrence of muscular weakness. There are only vague suggestions in these limited data that an excessive change in the extracellular-intracellular concentration ratio of potassium, at least, may be associated with weakness. More extensive measurements may in time establish or exclude what now appears to be only a hint, made especially tenuous by the fact that these patients were suffering from protracted illnesses accompanied variously by anemia, inanition, azotemia and multiple disturbances of electrolyte metabolism.

\section{SUM M ARY}

1. In normal muscle the mean values for potassium, magnesium and phosphorus and creatine were, respectively, $3.5 \mathrm{mEq}$., $0.61 \mathrm{mEq}$., 0.065 gm., and $0.138 \mathrm{gm}$., referred to one gm. of noncollagenous nitrogen ( $\mathrm{NCN})$.

2. In atrophied muscles the cation concentrations were reduced in terms of wet weight but, when referred to $\mathrm{NCN}$, were identical with the normal series.

3. The mean ratio of potassium to magnesium (referred to NCN) was 5.67, with a standard deviation of but 0.18 , for all muscles studied, whether normal, atrophied, or from patients with sweeping electrolyte distortions in serum leading to accumulation or loss of cations.

4. A similar, but not identical, constant relationship of potassium and of magnesium to total phosphorus was observed.

5. The mean creatine concentration in muscles containing less than $3.5 \mathrm{mEq}$. $\mathrm{K}$ per gm. $\mathrm{NCN}$ was significantly less than in those muscles with higher concentrations of potassium.

6. Constant intracellular proportions of potassium, magnesium and phosphorus were observed 
despite wide variations in the proportions of these substances in the serum.

\section{ACKNOWLEDGMENT}

The authors wish to express their gratitude to Drs. J. F. Crigler, Jr. and S. H. Silverman of the Department of Pediatrics for having made many of the potassium determinations; to Drs. S. L. Eversole and D. C. McGoon of the Department of Pathology for their interpretation of the microscopic sections; to Drs. R. F. Kieffer, Jr., and T. N. P. Johns, Resident Surgeons of the Johns Hopkins Hospital, and to the Resident Surgical Staff of the Baltimore City Hospitals for the surgical procedures, and to the Resident Medical Staff of the Osler Clinic of the Johns Hopkins Hospital for their assistance in the selection of clinical material. We are especially grateful to those patients who consented to undergo the surgical procedures for experimental purposes.

\section{REFERENCES}

1. Duncan, C. W., Huffman, C. F., and Robinson, C. S., Magnesium studies in calves. I. Tetany produced by a ration of milk or milk with various supplements. J. Biol. Chem., 1935, 108, 35.

2. Kruse, H. D., Schmidt, M. M., and McCollum, E. V., Studies on magnesium deficiency in animals. IV. Reaction to galvanic stimuli following magnesium deprivation. Am. J. Physiol., 1933, 105, 635.

3. Edmondson, H. A., Berne, C. J., Homann, R. E., Jr., and Wertman, M., Calcium, potassium, magnesium and amylase disturbances in acute pancreatitis. Am. J. Med., 1952, 12, 34.

4. Hirschfelder, A. D., and Haury, V. G., Clinical manifestations of high and low plasma magnesium. Dangers of epsom salt purgation in nephritis. J. A. M. A., 1934, 102, 1138.

5. Miller, J. F., Tetany due to deficiency in magnesium. Its occurrence in a child of six years with associated osteochondrosis of capital epiphysis of femur (Legg-Perthes disease). Am. J. Dis. Child., 1944, 67, 117.

6. Gardner, L. I., MacLachlan, E. A., Pick, W., Terry, M. L., and Butler, A. M., Etiologic factors in tetany of newly born infants. Pediatrics, 1950, 5, 228.

7. Szent-Györgyi, A., The contraction of myosin threads. Institute of Medical Chemistry, University of Szeged (Studies), Vol. 1, 1941-42, 17.

8. Euler, H. von, Nilsson, R., and Auhagen, E., Uber die Funktion des Magnesiums beim enzymatischen Kohlenhydratabbau. Ztschr. Physiol. Chem., 1931, 200, 1.

9. Lohmann, K., and Schuster, $\mathrm{Ph}$., Untersuchungen über die Cocarboxylase. Biochem. Ztschr., 1937, 294, 188.

10. Berger, J., and Johnson, M. J., Metal activation of peptidases. J. Biol. Chem., 1939, 130, 641.

11. Adler, E., Euler, H. v., Günther, G., and Plass, M.,
Isocitric dehydrogenase and glutamic acid synthesis in animal tissues. Biochem. J., 1939, 33, 1028.

12. Warburg, O., and Christian, W., Isolierung und Kristallisation des Gärungsferments Enolase. Biochem. Ztschr., 1941-42, 310, 384.

13. DuBois, K. P., Albaum, H. G., and Potter, V. R., Adenosine triphosphate in magnesium anesthesia. J. Biol. Chem., 1943, 147, 699.

14. Najjar, V. A., The isolation and properties of phosphoglucomutase. J. Biol. Chem., 1948, 175, 281.

15. Suomalainen, P., Production of artificial hibernation. Nature, 1938, 142, 1157.

16. Heagy, F. C., and Burton, A. C., Effect of intravenous injection of magnesium chloride on the body temperature of the unanesthetized dog, with some observations on magnesium levels and body temperature in man. Am. J. Physiol., 1948, 152, 407.

17. Hegnauer, A. H., Fenn, W. O., and Cobb, D. M., The cause of the rise in oxygen consumption of frog muscles in excess potassium. J. Cell. \& Comp. Physiol., 1934, 4, 505.

18. Gerard, R. W., and Tupikova, N., Creatine in nerve, muscle and brain. J. Cell. \& Comp. Physiol., 1938, $12,325$.

19. Boyer, P. D., Lardy, H. A., and Phillips, P. H., The rôle of potassium in muscle phosphorylations. J. Biol. Chem., 1942, 146, 673.

20. Briggs, A. P., and Koechig, I., Doisy, E. A., and Weber, C. J., Some changes in the composition of blood due to the injection of insulin. J. Biol. Chem., 1923-24, 58, 721.

21. Kamminga, C. E., Willebrands, A. F., Groen, J., and Blickman, J. R., Effect of insulin on the potassium and inorganic phosphate content of the medium in experiments with isolated rat diaphragms. Science, 1950, 111, 30.

22. Eliel, L. P., Hellman, L., Pearson, O. H., and Katz, B., The effects of ACTH on the electrolyte content of various body tissues, in Proceedings of the Second Clinical ACTH Conference, edited by Mote, J. R., The Blakiston Co., New York, 1951, Vol. I, p. 196.

23. Potter, V. R., The homogenate technique, in Methods in Medical Research. Potter, V. R., ed., Year Book Publishers, Inc., Chicago, 1948, Vol. I, p. 317.

24. Lilienthal, J. L., Jr., Zierler, K. L., Folk, B. P., Buka, R., and Riley, M. J., A reference base and system for analysis of muscle constituents. J. Biol. Chem., 1950, 182, 501.

25. Peters, J. H., The determination of creatinine and creatine in blood and urine with the photoelectric colorimeter. J. Biol. Chem., 1942, 146, 179.

26. Fischer, E., and Ramsey, V. W., Changes in protein content and in some physicochemical properties of the protein during muscular atrophies of various types. Am. J. Physiol., 1946, 145, 571.

27. Shohl, A. T., Mineral metabolism. Reinhold Publishing Corp., New York, N. Y., 1939, Chap. 2, p. 13. 
28. Buell, M. V., and Turner, E., Cation distribution in the muscles of adrenalectomized rats. Am. J. Physiol., 1941, 134, 225.

29. Fenn, W. O., and Haege, L. F., The penetration of magnesium into frog muscle. J. Cell. \& Comp. Physiol., 1942, 19, 37.

30. Gardner, L. I., Talbot, N. B., Cook, C. D., Berman, H., and Uribe, R. C., The effect of potassium deficiency on carbohydrate metabolism. J. Lab. \& Clin. Med., 1950, 35, 592.

31. Cotlove, E., Holliday, M. A., Schwartz, R., and Wallace, W. M., Effects of electrolyte depletion and acid-base disturbance on muscle cations. Am. J. Physiol., 1951, 167, 665.

32. Kaplan, N. O., Franks, M., Friedgood, C. E., Metabolism in diabetic coma produced by alloxan. Science, 1945, $102,447$.

33. Flock, E., Bollman, J. L., Mann, F. C., and Kendall, E. C., The effect of the intravenous injection of glucose and other substances on the concentration of potassium in the serum of the dog. J. Biol. Chem., 1938, 125, 57.

34. Atchley, D. W., Loeb, R. F., Richards, D. W., Jr., Benedict, E. M., and Driscoll, M. E., On diabetic acidosis. A detailed study of electrolyte balances following the withdrawal and reestablishment of insulin therapy. J. Clin. Invest., 1933, 12, 297.

35. Butler, A. M., Talbot, N. B., Burnett, C. H., Stanbury, J. B., and MacLachlan, E. A., Metabolic studies in diabetic coma. Tr. A. Am. Phys., 1947, 60, 102.

36. Butler, A. M., Parenteral fluid therapy in diabetic coma. Acta Pædiat., 1949, 38, 59.

37. Martin, H. E., and Wertman, M., Serum potassium, magnesium, and calcium levels in diabetic acidosis. J. Clin. Invest., 1947, 26, 217.

38. Mangun, G. H., Reichle, H. S., and Myers, V. C., Further studies on human cardiac and voluntary muscle. Possible implications of changes in the creatine, phosphorus and potassium content, with special reference to heart disease. Arch. Int. Med., 1941, 67, 320.

39. LePage, G. A., Biological energy transformations during shock as shown by tissue analyses. Am. J. Physiol., 1946, 146, 267.

40. Chanutin, A., Studies on the creatine and nitrogen content of the whole rat after the feeding of a variety of diets and after nephrectomy. J. Biol. Chem., 1930, 89, 765.

41. Coffman, J. R., and Koch, F. C., The effect of testosterone propionate on induced creatinuria in rats. J. Biol. Chem., 1940, 135, 519.

42. Folk, B. P., Zierler, K. L., and Lilienthal, J. L., Jr., Distribution of potassium and sodium between serum and certain extracellular fluids in man. Am. J. Physiol., 1948, 153, 381.

43. Berliner, R. W., Kennedy, T. J., Jr., and Hilton, J. G., Renal mechanisms for the excretion of potassium. Am. J. Physiol., 1950, 162, 348.

44. Hastings, A. B., Salvesen, H. A., Sendroy, J., Jr., and Van Slyke, D. D., Studies of gas and electrolyte equilibria in the blood. IX. The distribution of electrolytes between transudates and serum. J. Gen. Physiol., 1927, 8, 701.

45. Soffer, L. J., Dantes, D. A., Grossman, E. B., Sobotka, H., and Jacobs, M. D., Ultrafiltrable magnesium in hyperthyroidism. J. Clin. Invest., 1939, 18, 597.

46. Ling, G., Selective ionic accumulation in muscle cells. Federation Proc., 1952, 11 (Part 1), 95. 